\title{
A Seleção de Pessoal em Psicologia em Questão
}

\author{
Selection of Personnel in Psychology
}

La Selección de Personas en la Psicología en Cuestión

Ana Maria Lopez Calvo de Feijoo \& Elina Eunice Montechiari Pietrani

Universidade Federal do Rio de Janeiro 
Resumo: O objetivo deste trabalho consiste em tecer uma análise crítica do processo de seleção de pessoal em Psicologia, que, aliando-se às concepções descritas por Heidegger como a era da técnica, que detém como verdades algumas características como fundo de reserva, funcionalidade (utilidade) e a produtividade sem limites, expõe a capacidade produtiva como requisito fundamental para aquele que busca um posto de trabalho. Ocorre que, ao tomar esse critério como a única e absoluta verdade da capacidade do trabalhador, outras capacidades e motivações, quando muito, ficam relegadas a um segundo plano. O homem, assim tomado, passa a se comportar de modo autômato, tal como a máquina, cuja utilidade dura enquanto durar a necessidade de sua produção, sendo descartado quando outras necessidades se sobrepõem àquela. Pretende-se, por meio de uma visada fenomenológico-hermenêutica do processo de seleção de pessoal em Psicologia, poder abrir outras possibilidades de pensar o homem, o trabalho e o processo seletivo em suas inter-relações.

Palavras-chave: Psicologia. Seleção de pessoal. Heidegger. Produtividade.

Abstract: The aim of this paper is to provide a critical analysis of the personnel selection process in Psychology. Psychology allies itself to the concepts described by Heidegger as the era of technology, holding as truths characteristics, such as reserve fund, function (utility), and productivity without limits, exposing productive capacity as fundamental to a job-seeking person. Considering this criterion as the only truth along with the capacity of the worker, other capabilities and motivations, at best, are relegated to the background. The man, so taken, shall behave like automation, a machine whose usefulness lasts as long as there is a need for its production and which is discarded when other needs overtake that. The goal is that using a phenomenological-hermeneutic sight of personnel selection, this could open up other possibilities for thinking about the man and his work and the selection process that occurs in this relationship.

Keywords: Psychology. Personnel selection. Heidegger. Productivity.

Resumen: El objetivo de este estudio es hacer un análisis crítico de la selección de personal en Psicología, que al aliarse con los conceptos que caracterizan esta época como la era de la técnica y que sostiene como verdades algunas características, tales como: fondo de reserva, funcionalidad y la productividad sin límites, expone la capacidad productiva como un requisito clave para la persona que busca un trabajo. Al considerar este criterio como único y absoluto, la capacidad y motivaciones de los trabajadores, se ven relegados a un segundo plano. El hombre, visto de esa manera, se comporta de modo autómata, como máquina cuya utilidad dura por la necesidad de su producción y es descartado cuando otras necesidades se superponen a eso. La intención es utilizar una vista fenomenológico-hermenéutica de la selección de personal en psicología, para que así se puedan abrir otras posibilidades de pensar del hombre, el trabajo y el proceso de selección que se lleva a cabo en esta interrelación.

Palabras clave: Psicología. Elección de personas. Heidegger. Productividad.

\section{Introdução}

A ideia de problematizar o processo de seleção de pessoal em Psicologia surgiu frente às declarações de candidatos a vagas de empregos, ouvidas no cotidiano da prática profissional nas empresas e observadas nas redes sociais de Internet ${ }^{1}$. Essas declarações, em grande parte, levantam dúvidas e geram descrenças sobre a eficiência e a validade dos métodos e técnicas empregados pela Psicologia no processo de seleção, descritas como técnicas massificadoras, que não observam as especificidades dos candidatos. Os comentários costumam atingir até mesmo, de forma mais direta, a figura do selecionador de pessoal, os quais, misturados entre tons de ironia, humor ou mesmo desprezo, o descrevem como um profissional de postura conservadora, que não atualiza seus métodos de trabalho à dinâmica do mercado, pouco 
preparado, metido a besta e orgulhoso, que emite perguntas estereotipadas e, consequentemente, recebe respostas estereotipadas ${ }^{2}$. Além disso, há outra crítica que se dirige ao profissional de psicologia que diz respeito à desconsideração desse profissional com relação ao candidato. É significativo o número de candidatos que declaram não receber nenhum retorno a respeito do resultado dos processos seletivos, deixando-os muito frustrados e sem rumo, algo que não condiz ao projeto da Psicologia em sua totalidade.

Em uma análise imediata dos comentários acima relacionados, pergunta-se em que medida essas declarações, que se refere a percepções do senso comum, as quais, em tese, ignoram as bases científicas que norteiam o processo de seleção e a própria Psicologia, devem ser consideradas. Mas, por outro lado, não caberia questionar se as declarações dos candidatos estariam apontando para um equívoco inerente ao processo seletivo? Caso positivo, qual seria o equívoco para o qual o senso comum estaria apontando?

Castañon (2004) e Ribeiro (2008) têm, a seu modo, alertado para o fato de a Psicologia ter assumido uma posição de total objetividade e racionalidade com a finalidade de antecipação (diagnóstico) e controle (prognóstico) frente às questões do homem na sua lida existencial. A seleção de pessoal na Psicologia, por sua vez, tal como se estabeleceu na era moderna, ao limitar seu fazer à identificação do homem como fator produtivo, parece confirmar as concepções desses dois autores, uma vez que toma como base a "matematização e instrumentalização da experiência, quando não na racionalidade pura (lógica e matemática)" (Castañon, 2004, p. 156) no modo como conduz tal processo.

Ribeiro (2008) é enfática quando afirma que "o fenômeno humano não pode ser apreendido estatisticamente. Mensurar o ser humano significa descaracterizá-lo" (p. 174), significa reduzir o homem a uma relação de coisificação com os outros homens e com o mundo, uma vez que abandona a constituição histórica bem como desconsidera o caráter de articulação de sentido sempre em jogo em que a existência se dá.

Com base nas críticas acima expostas, refletirse-á em seguida sobre o modo com que a seleção de pessoal se desenvolve pela Psicologia no horizonte histórico de constituição de sentido na era moderna. Primeiramente, buscaremos tecer uma análise crítica sobre o processo seletivo tendo em vista os atributos que norteiam essa era como uma era em que a produtividade incessante se coloca como sua tônica, requisitando comportamentos e orientando fazeres.

Revisitando a trajetória da Psicologia desde que ela se inseriu no contexto organizacional, concomitantemente ao período em que esse contexto sofria grandes transformações em seu processo produtivo, apontar-se-á como se apresenta a ênfase na determinação da produtividade. A partir do período da industrialização clássica, a Administração Científica de Frederick Taylor buscava nos conceitos da então jovem Psicologia formas de tornar mensuráveis a seleção e o desempenho do homem no trabalho. Gradativamente, junto às mudanças ocasionadas pelo processo tecnológico que transformou os modos de produção, a Psicologia continuou marcando seu espaço no ambiente de trabalho, para gerenciar os "ativos intangíveis" (Chiavenato, 2010, p. 55) das organizações, sempre em consonância às determinações de cada época. Desde a Administração Científica, introduzida por Frederick Taylor, até o modelo Toyota de gestão empresarial, a Psicologia do Trabalho determinou sua atuação e continuou, ao longo do tempo, compartilhando sua prática nos diferentes cenários econômicos que se estabeleceram, mantendo sempre o projeto de encontrar o trabalhador capaz de produzir em seu potencial máximo.

Estudiosos da temática homem-trabalho, como Dejours (2005), Dejours, Abdoucheli e Jayet (2012), Schwartz (2010a) e Sennett (2006, 2012) buscaram efetuar uma análise crítica a esse modelo hegemônico de trabalho que só leva em conta a utilização do homem como um elemento a atender os requisitos de produtividade e eficiência 
organizacional. São essas, respectivamente, perspectivas na ordem do social, da psicodinâmica e da filosofia-ergológica que, embora se orientem por outros caminhos, suscitam aspectos que alimentam nossas inquietações sobre a seleção de pessoal tal como realizada pela Psicologia.

Por fim, com base nas reflexões de Martin Heidegger sobre verdade, técnica e com seu método de investigação, qual seja, fenomenológico-hermenêutico, seguir-se-á o caminho para percorrer as questões, da ordem da relação homem-trabalho, que trazem inquietações, ao mesmo tempo em que, por meio da fenomenologia hermenêutica, proceder-se-á a uma reflexão que, à primeira vista, parece discutir o óbvio, para, em seguida, levar à compreensão do óbvio que se encontra esquecido em meio aos afazeres do mundo moderno. Fascinado pelo magnetismo do pensamento técnicocalculante, o homem parece se esquecer de meditar sobre sua existência, a qual é tomada, na maior parte das vezes, pela facticidade da era da técnica, como um ente produtivo, tal qual uma máquina que é usada até a exaustão e depois descartada.

Na construção das reflexões, ver-se-á que a Psicologia é constantemente interpelada pela era da técnica para se inserir nesse contexto e responder a ela, dando voz à Psicologia. A Psicologia, como ciência que se estabeleceu e empreendeu seu fazer tomando os caracteres da era da técnica como verdades absolutas. Dessa forma, seu modelo de seleção de pessoal também se estabeleceu sob as verdades absolutas desse horizonte histórico. O homem, tomado pela Psicologia como uma estocagem, fundo de reserva e analisado exclusivamente sob o prisma da funcionalidade a serviço da produtividade, é concebido estritamente pelo que ele pode oferecer em termos de resultados e desempenhos. Ao delimitar a existência humana por esses aspectos, a Psicologia deixa esquecida a importância do candidato a um posto de trabalho em mostrar-se naquilo que é o sentido de sua existência, intervindo, assim, em seu modo próprio de ser. O homem, num esforço infatigável de se adequar às interpelações da técnica moderna traduzidas nos elementos do processo de seleção, acaba por ver suprimida a possibilidade de uma relação com o trabalho sedimentada na liberdade do homem em tudo aquilo que ele pode ser e fazer. A Psicologia, ao agir no processo de seleção unicamente pelas evocações da técnica moderna, acaba por consolidar a relação homem-trabalho em bases preponderantemente deterministas e disciplinares e, como tal, aprisionadoras.

Seguindo o caminho heideggeriano, não é proposta deste trabalho responder o que é o processo de seleção pela Psicologia, mas, a partir das concepções daquele pensador, refletir sobre os sentidos desse fazer pela Psicologia dentro de um contexto histórico notadamente marcado pela cientificidade do pensamento. Acredita-se que as discussões aqui apresentadas suscitem a necessidade de se pensar a Psicologia no processo de seleção a partir de um novo começo. A partir de um novo começo que não significa destituir-se do modelo lançado, mas, ao modo heideggeriano, partir dele e, refletindo sobre ele, poder buscar caminhos possíveis.

Para problematizar o processo de seleção de pessoal, inicia-se por questionar o modelo empregado pela Psicologia do Trabalho, o qual indica se encontrar imerso nas determinações de mundo próprias àquela que Heidegger denominou a era da técnica (2007). Segundo o pensador, a era da técnica teria se iniciado com o período conhecido como a era moderna. Esta, por sua vez, é entendida como um tempo determinado por um novo projeto metafísico fundamental, isto é, por uma nova interpretação das coisas na sua totalidade e por uma nova apreensão da verdade. Esse tempo passou a ocorrer a partir do momento em que o homem abandonou a capacidade e a disposição para a reflexão sobre as coisas que aconteciam e se deixou atravessar pelo domínio exclusivo da ciência, em que o pensamento que prevalece sobre todas as coisas é o pensamento técnico-calculante. Neste, as relações sejam de que natureza for se estabelecem pelo nexo causal, como uma relação de causa e efeito, um meio para se chegar a um fim. 
Seguir-se-á, na investigação do fenômeno do processo de seleção de pessoal, o método fenomenológico-hermenêutico tal como idealizado por Heidegger (1963/1991). A base fenomenológica em Heidegger procede de uma inspiração husserliana e significa ir às coisas mesmas, suspendendo todas as suposições teóricas acerca desse fenômeno. Já a hermenêutica diz respeito ao fato de que qualquer interpretação deve levar em consideração o horizonte histórico em que o fenômeno se encontra, neste caso a era da técnica Tudo isso sem abandonar o traço fundamental correspondente do método grego que é a conservação e a 'salvação' dos fenômenos que se mostram, deixados intocados e incólumes, o puro deixar-estar-presente daquilo que se mostra.

O método usado por Heidegger pode ser indicado como um envolver-se especialmente na relação com o que se encontra. Faz parte da fenomenologia o ato de vontade de não se fechar contra este envolver-se. Assim é que se pretende neste trabalho alcançar o que acontece no processo seletivo permanecendo totalmente envolvido com o acontecimento.

Cabe lembrar que Heidegger (2009) não rejeita a ciência como tal, mas recusa a sua pretensão ao absoluto, a ser o parâmetro de todas as verdades, pretensão que descreve como inaceitável. Prossegue Heidegger, ressaltando que como ente verdadeiro, para a ciência, vale o que é verificado por objetividade científica, que só é possível na medida em que o homem admitiu sua subjetividade, a qual não pode ser compreendida de imediato. Lembra que Kant submeteu, pela primeira vez, o princípio de Descartes referente à definição da objetividade do objeto a uma analítica sistemática em sua Crítica da Razão Pura e que Husserl precisou, desdobrou e fundamentou esta posição de Kant fenomenologicamente. Já Ser e tempo, ao contrário do pensamento usual da metafísica, coloca uma questão diferente, qual seja a do sentido do ser. Se até então se questionava o ente com referência ao seu ser, em Ser e tempo a pergunta não é mais pelo ente como tal, "mas pelo ser como tal, pelo sentido do ser em geral, pela abertura de ser possível" (Heidegger, 1927/2012, p. 145).
Heidegger (2007) esclarece sobre o horizonte de sentido em que o homem se encontra, que ele denominou de Era da Técnica. O filósofo insiste em destacar o caráter de esquecimento da essencialidade da existência como herança da metafísica, da qual a ciência é debitária. Na tentativa de despertar o homem para esse total esquecimento, esse filósofo vai escrever seu texto $A$ Era da Técnica em que afirma que, em nosso tempo, a verdade do ser reside no esquecimento. Esquecer, então, consiste em encurtar sentidos. A Psicologia, ao se encontrar totalmente inserida nas determinações da era da técnica quais sejam: provocação (exploração), fundo de reserva (acumulação), maquinação, funcionalidade (serventia) e a produtividade, não estaria apoiando o seu fazer na técnica oriunda dos avanços científicos? Desse modo, a Psicologia estaria restringindo o seu fazer a uma produtividade que se mede pela qualidade de vida, pela felicidade e pelo bem-estar, encurtando assim sentidos possíveis?

O sentido da técnica moderna, Gestell, pautou-se no objetivo da ciência, que consistia em buscar um caminho certo e seguro sobre a verdade e consequente resolução das coisas. Por meio de um discurso exato, em que predomina o princípio de identidade e a idealização matemática, o método tornou-se mais importante em toda e qualquer investigação, até mesmo do que o tema a ser investigado. Gestell é compreendido por Heidegger (2007) como o acontecimento apropriativo que responde pela técnica com suas determinações, descritas a seguir.

\section{Provocação, fundo de reserva, funcionalidade e produtividade}

Heidegger (2012), ao esclarecer sobre as determinações de sentido que se estabelecem na atualidade, dá relevo ao fato de que o homem tende, no início e na maior parte das vezes, a assumir as determinações do mundo que é o seu. Ou seja, o homem passa a comportar-se de modo a corresponder às determinações de sua época. Essas determinações vêm, constantemente, ao encontro e requerem um co-responder. 
Nesse corresponder do homem àquilo que Ihe vem ao encontro e considerando o caráter técnico-calculante da era moderna, é que esse homem passa a tomar-se também como um objeto quantificável e calculável. Nessa era, em que as coisas movimentam-se por meio da ação incessante, dada a ênfase na produtividade com fins de acúmulo e descarte em um circulo vicioso, e que tudo acontece de modo autômato, o homem, imerso nessas determinações, tende a comportar-se também como autômato em direção à produtividade. Assim, não só as ciências, disciplinas, fazeres do homem, mas também o próprio homem segue a cadência do mundo moderno, sob a lógica da produção. Nesse sentido, pode-se afirmar que a era moderna, tomada que é pelos sentidos do cálculo e da mensuração, detém algumas características, como: provocação, fundo de reserva, funcionalidade (serventia) e a produtividade (Heidegger, 2007).

A provocação remete ao fato de a técnica moderna desafiar a natureza ininterruptamente para utilizá-la com fins à exploração. $O$ homem, esquecido da possibilidade de uma lida com a natureza ao modo do cultivo e do cuidado, como era próprio dos camponeses na era medieval, passou a tomá-la como recurso a ser explorado exaustivamente e, dessa forma, passou também a provocá-la, a dispor dela como matéria-prima abundante e utilizá-la de forma a obter o máximo de rendimento possível com um mínimo de gasto.

Por fundo de reserva, refere-se ao acúmulo de coisas como fazeres, saberes, bens, verdades, etc., que o homem busca reter de modo ilimitado, de forma a estabelecer uma "reserva" de estocagem e atender, assim, às demandas próprias da era da técnica e acabando ele próprio se tornando fundo de reserva.

A funcionalidade ou serventia é tomada em um papel utilitário, como são tomadas todas as coisas no horizonte da técnica. Nesse horizonte tudo se encontra em função de algo. Tudo é função de um grande sistema, que se movimenta ininterruptamente para que, em última instância, a técnica prevaleça. Vê-se, assim, que todas as coisas e relações são tomadas pelo seu caráter utilitarista, do manuseio e do uso.

Os pressupostos definidos brevemente acima remetem a esta que pode ser considerada a principal temática da era da técnica: a produtividade ou a produção incessante. $\mathrm{O}$ provocar a natureza, o acúmulo para obtenção de fundo de reserva, o fazer incessante e contínuo na maquinação e a tomada das coisas pelo seu caráter estritamente funcional levam ao objetivo de produzir ilimitadamente, como um modo em que esse produzir não cesse. Todo o caminhar do homem moderno conduz à busca pela eficiência dos processos, pelos resultados mais espetaculares, pelo destaque em relação aos demais. Por esses modos que caracterizam a produtividade na era moderna, vê-se o homem ser tomado como um fator produtivo e naturalmente descartado, ao ser constatada sua inutilidade frente aos chamados desse horizonte histórico. O pensamento técnico-calculante, concebido como pensamento capital da era moderna, determina, assim, o homem como um autômato tal qual a máquina, também disponível à produtividade contínua e do qual deve ser extraído todo o rendimento possível. É preciso que a produtividade nunca cesse e a técnica não perca seu lugar na existência.

Esses atributos, que se encontram incrustados como verdades estabelecidas pela era moderna e atravessam os modos de o homem se relacionar com as diversas instâncias da sua existência, constituem-se como premissas de um mundo que somente se concebe pelo tecnicismo das relações. Portanto, a compreensão do que caracteriza a era da técnica, com os atributos acima mencionados, passa também pela compreensão da concepção de verdade como adequação, uma vez que esses atributos são tomados como verdades inquestionáveis e naturais dentro desse horizonte histórico.

A concepção de verdade associada à razão, que, por sua vez, se associa aos atributos da produtividade moderna, vai ao encontro de uma era em que o homem, com as descobertas da ciência, descobre um novo mundo diante de si. Trata-se de um mundo desprendido 
do poder dos mitos e da religião, os quais colocavam o homem em uma posição de submissão e incapacidade, e que agora passa a ser apreendido e supostamente controlado por esse mesmo homem, por intermédio do saber científico. Suportado pela ciência e amparado pela razão, o homem se desprende do seu papel de um ente submetido aos dogmas religiosos e passa a crer em seu poder de dominar a natureza e tudo que nela existe.

\section{Psicologia: ciência e verdade}

A Psicologia parece ter se alinhado à concepção de verdade como representação, que se consolidou na modernidade e que, como ciência, a inspirou. Obedece, assim, à lógica de um pensamento que prescreve que o homem deve ser imbuído de comportamentos em consonância à dinâmica do que está em jogo pelo contexto histórico vigente. É baseada nessa concepção determinista que a Psicologia parece ter construído seu fazer no ambiente de trabalho e, por conseguinte, o processo de seleção de pessoal. Ou seja, baseando-se nas determinações de um contexto histórico que concebe o homem exclusivamente pelo seu caráter produtivista, a Psicologia desenvolveu o modo de selecionar pessoas, buscando identificar nelas os atributos propostos por esse horizonte técnico.

Pela concepção moderna de seleção de pessoal assumida pela Psicologia, verificase que essa ciência se orienta na busca pela identificação do modo de ser do candidato e seu grau de adequação aos requisitos de um sistema organizacional que, por sua vez, se encontra inserido em um contexto profundamente marcado pelos atributos da era da técnica. Em outras palavras, ao procurar a verdade do candidato, a Psicologia busca-a tendo como parâmetro as determinações de um determinado horizonte histórico. Ora, uma vez que o horizonte histórico da atualidade toma as concepções de produtividade, funcionalidade e acúmulo (fundo de reserva) como verdades indubitáveis, encontra-se um modelo de seleção de pessoal totalmente envolvido por esses pressupostos.
Trata-se, no entanto, de pressupostos que, no expediente corporativo, recebem outra roupagem e são denominados como "competências comportamentais" (Leme 2007, p. 33; Pontes 2010, p. 175). As competências comportamentais compõem, de forma geral, o rol de exigências das empresas na atualidade, que, vistas em sua totalidade, deixam claro o caráter de convocação do homem a assumir o papel produtivista que lhe é reservado no atual modelo de empregabilidade, colocando-se como um reservatório de energia a ser constantemente utilizado pelas organizações. Tomado como dogma absoluto e inquestionável, esse modelo põe à margem do mercado de trabalho pessoas que não se apresentam mediante essas determinações e desconsidera quaisquer outros modos possíveis de o homem se comportar em relação ao seu trabalho.

Vê-se que essa forma de realização do processo seletivo é corroborada por diversos teóricos da área, como Chiavenato (2010), que vê o processo de seleção como "um sistema de comparação e de escolha (tomada de decisão)" (p. 139), ao confrontar as prescrições do cargo com o perfil do candidato. Na mesma linha de pensamento, Pontes (2010) refere-se à "análise de cargos por competência como instrumento para o recrutamento e seleção" (p. 59), considerando que "as competências definem comportamentos das pessoas para atender as necessidades corporativas" (p. 59). Leme (2007) vai mais longe, ao elaborar o "Inventário Comportamental para Mapeamento de Competências" (p. 39) como "uma metodologia que permite a identificação das competências comportamentais necessárias para que a empresa possa agir alinhada a sua Missão, Visão e Valores" (p. 39).

No cotidiano das organizações, essa concepção de seleção de pessoal parece ser ainda mais natural quando psicólogos atuantes nas áreas de Recursos Humanos declaram que as pessoas são um recurso a ser empregado pela empresa, não se abrindo a outras formas de realização do processo de contratação de pessoal. Observa-se também que não só o processo de seleção, mas os demais processos desenvolvidos pelos psicólogos 
nas organizações, como avaliações de desempenhos, programas de treinamento, etc., parecem ser conduzidos, visando exclusivamente à previsão e ao controle do homem, de forma a tê-lo como um meio para atingir resultados. Da mesma forma que os demais recursos da empresa, o trabalhador parece se equiparar a uma grande máquina que pode, não só ser investigado, mas também regido, com todo o rigor e precisão, pelas mesmas leis aplicadas às máquinas e, portanto, passível de previsão e controle.

As questões que se impõem frente à proposta crítica a esse modelo de seleção hegemônico são: até que ponto a Psicologia, comprometida com o processo de seleção, compactua, sedimenta e fortalece essa forma de pensar em que o homem fica equiparado à máquina? Poderia a Psicologia assumir outra posição frente ao modo de estabelecer o processo de seleção, de forma a não tomar o homem apenas como um fator produtivo?

\section{Crítica ao modelo tradicional de seleção de pessoal}

De posse desses questionamentos, refletir-se-á sobre a possibilidade de poder caminhar no sentido de abrir outros modos para o processo de seleção, tendo como princípios norteadores as reflexões heideggerianas acerca da era da técnica e seus pressupostos de verdade.

Esse modelo de seleção atualmente praticado pela Psicologia que pretendemos analisar parece ter se iniciado desde o período da industrialização, quando o feudalismo foi gradualmente substituído pelo sistema capitalista de produção, num período em que, simultaneamente, a ciência impunha o seu domínio em todas as esferas da existência. Absorvido pela cientificidade e mecanização do universo, a Revolução Industrial demarcou uma nova era ao substituir o modelo de produção artesanal pelo método industrial, e o sistema econômico capitalista. Desde então, fixou seus fundamentos ao impor uma difusão global da produção e do consumo. Esses fundamentos, baseados na privatização dos meios de produção e no lucro, afetaram profundamente a relação trabalhador-empresa e vêm ditando as verdades da era moderna, assegurando como natural a exigência cada vez mais crescente da produtividade e flexibilidade como modelo por excelência do sistema de produção.

A Psicologia, que se estabeleceu como ciência paralelamente à ascensão do sistema capitalista de produção, vem acompanhando e atuando conjuntamente com as transformações que se sucederam no ambiente de trabalho. Desde o modelo de gestão voltado para a racionalização do sistema de produção tal como implantado por Taylor na era industrial clássica, até o modelo de gestão empresarial voltado preponderantemente à flexibilidade e fluidez dos sistemas (toyotização), a Psicologia vem compartilhando tais períodos com seus constructos e aplicações do seu saber.

Desde então, verifica-se que o modelo de seleção de pessoal, através do qual a Psicologia marcou seu ingresso e sustentou seu status de ciência no ambiente corporativo (Lima, Costa \& Yamamoto, 2011), vem se desenvolvendo e se consolidando ao longo do tempo como um modelo baseado nas concepções científicas e socioeconômicas de cada período.

Alinhado às determinações desse horizonte técnico-científico, o processo de seleção pela Psicologia vem atuando na rigorosa busca do "homem certo para o lugar certo" (Pontes, 2010, p. 29), enunciado que perpassou durante muito tempo o conceito de seleção de pessoal e que até hoje parece manter sua influência. O modelo de seleção adotado pela Psicologia consolidou-se, assim, como seu referencial em um contexto eminentemente marcado pela verdade enquanto sinônimo de produtividade e descarte; um contexto que determina que as pessoas sejam avaliadas pela sua capacidade expressa de gerar resultados, ao mesmo tempo em que seu período de permanência na empresa balança ao ritmo das movimentações do negócio, ficando o trabalhador à mercê dessas articulações. 
Encontra-se aí o pressuposto da funcionalidade no que diz respeito à serventia do homem, servindo-se a um propósito, sem jamais poder deixar de servir e que, ao perder sua serventia, torna-se supérfluo e pode ser descartado. Na lógica subjacente do contexto do trabalho, sob a ameaça constante do desemprego, o homem se afigura como um fundo de reserva, um estoque de matéria-prima sempre pronta a suprir as necessidades da empresa.

Ocorre que, ao se considerar a produtividade a única e absoluta verdade acerca da capacidade do trabalhador, o homem fica reduzido a um ente substancializado e tomado por atributos meramente calculáveis, objetificando, desse modo, a existência.

A metodologia adotada pela Psicologia no processo de seleção obedece ao método das ciências naturais no que diz respeito à calculabilidade e à previsibilidade do objeto de estudo. Segundo Rodrigues, Assmar e Jablonski (2012), o método da ciência moderna se baseia em procedimentos padronizados, os quais incluem: uma teoria prévia, o levantamento de hipóteses, teste empírico das hipóteses, análise dos dados, confirmação ou rejeição das hipóteses e a posterior generalização dos resultados. Ao tomar a produtividade como a verdade do seu fazer (teoria prévia), analisar o candidato com base nessas verdades, rejeitá-lo ou aprová-lo tendo como base unicamente o resultado emitidos pelas ferramentas aplicadas (testes psicológicos, entrevistas, dinâmicas de grupo, etc.), o processo de seleção se imbui de características em que o objeto de estudo nada mais é do que o homem - candidato a vaga de emprego. Com esse modelo de seleção, esse homem fica totalmente à mercê de um conjunto de procedimentos padronizados, que ignora sua existência e os sentidos que ela oferece para si mesmo.

A calculabilidade do método científico limita o objeto pesquisado dentro dos objetivos que se deseja atingir. Ele não é examinado sob suas outras possibilidades, mas permanece restrito ao objetivo do pesquisador. O objeto, bem como as observações resultantes de sua análise, não excede os limites demarcados pela proposição prévia.

Para Heidegger (2012), no entanto, a concepção de homem como ente substancializado e objetificado encobre a possibilidade de uma compreensão autêntica do homem enquanto um ser que é constituído e se constitui na inseparabilidade eu-mundo, um ser-aí. Essa concepção heideggeriana, aliada à noção de poder-ser do homem, remete à ideia de que tanto a situação histórica quanto o homem, em sua capacidade de transcendência, tendem a se movimentar continuamente no jogo dinâmico da existência e, portanto, não podem ser apreendidos pela mensuração e controle.

A Psicologia, ao agir conforme os pressupostos exclusivamente técnico-calculantes distancia-se do ser mais próprio do homem e objetualiza sua existência. Ao partir de uma perspectiva pré-determinada, em meio a uma era de sentidos planejados e calculados, o sentido do ser fica obscurecido, ou seja, o sentido que é dado pelo próprio homem na sua relação com o mundo se desqualifica. Ao instrumentalizar a relação com o candidato à vaga de emprego, a Psicologia do Trabalho parece se esquecer do caráter histórico-temporal em que está em jogo a existência; ignora os aspectos mundanos que a percorrem, com os quais o homem, na relação com o mundo, com-partilha seu modo próprio de ser. Ao orientar seu trabalho por verdades pré-determinadas, a Psicologia se distancia da existência humana, ratificando uma herança mecanicista, na qual foi concebida. Fragmenta, assim, o homem, estudando-o, analisando-o, tomando-o como um objeto contemplativo e não uma existência integral e em movimento constante.

No modelo tradicional de seleção, a Psicologia parece tomar o homem como um ente dotado de uma substância - racional ou emocional - localizável no tempo e no espaço, dotado de determinações e sentidos e que se relaciona com o mundo de forma dicotomizada, o que evidencia a ideia de homem - candidato à vaga de emprego totalmente baseada na ideia de que se trata 
de um ente simplesmente dado (Heidegger, 2012). Com base nessa noção de ente, e como tal pode ser mensurado, avaliado e delimitado, alinhando-se aos atributos da era da técnica, a Psicologia parece se relacionar com o candidato da mesma forma que a Física se estrutura em termos de causa e efeito, matéria, força, leis etc. Antes de lançar mão dos métodos, o processo de seleção pela Psicologia parece se encontrar antecipado por um modo de pensar científico totalmente orientado que toma o homem em um modo entificado e, portanto, calculável e previsível.

O modelo de seleção empregado pela Psicologia vai de encontro à concepção fenomenológico-hermenêutica, a qual se apresenta como uma tentativa de desobjetificação da existência humana. Como descreve Casanova (2006), "como o ser-aí é um ente marcado pelo caráter modal da possibilidade, ele não possui nenhuma propriedade simplesmente subsistente e não pode ser, em consequência, determinado em sua quididade específica" (p. 17). Nessa concepção, a Psicologia, com seu modelo técnico-científico, desconsideraria, no seu fazer da seleção, algumas questões, tais como desenvolvidas por Heidegger (2012):

Primeiro: o caráter de imanência em que a existência se dá em sua co-originalidade. A concepção de Dasein, o ser-aí, parece ser descartada quando se ignoram as bases de uma existência em que homem e mundo são co-pertencentes e convivem em um caráter de inseparabilidade plena. Essas duas instâncias, homem e mundo, na concepção heideggeriana não se relacionam enquanto instâncias isoladas, mas se revelam em sua copertinência mútua, no fenômeno do existir. A existência é, logo, anterior a qualquer conceituação, pois se constitui sempre nesse espaço de articulação homem-mundo.

Segundo: o caráter de indeterminação da existência na constituição ontológica do ser-aí se dá na sua cotidianidade mediana, modo em que o ser-aí se encontra de início e na maior parte das vezes. Essa sustentação fática sedimentada fornece as orientações necessárias à realização do ser-aí, ao seu poder-ser. O ser-aí parte dessa sustentação para fazer valer o seu caráter de transcendência. Ao considerar o ser-aí como um ser cuja existência se constrói no cotidiano do existir, quer-se reafirmar aqui o pensamento heideggeriano (2012), segundo o qual o homem não pode ser enquadrado em delimitações, quantificações, conceituações, por se tratar de uma existência que se dá no próprio movimento do existir. $\mathrm{O}$ termo ek-sistente, em seu significado de "estar aberto e lançado para fora" (Cabral, 2004, p. 49), traduz essa concepção. Essa abertura, mais do que dispor o homem ao mundo, diz respeito de forma essencial à incompletude fundamental que já sempre projeta o ser-aí para o aberto da existência, aponta para a indeterminação na qual a própria existência se encontra desde sempre.

Retomando-se a ideia do método no processo de seleção, pretende-se aqui revisitar o método fenomenológico-hermenêutico, em Heidegger, que é associado ao pensamento grego, significando "o caminho que leva a algo, uma área, o caminho pelo qual estudamos um assunto" (Heidegger, 2009). Essa concepção toma como base a indeterminação do próprio caminho, não se pode, portanto, estabelecer de antemão, sem mais nem menos, de que maneira o assunto determina a espécie de caminho que a ele conduz, de que maneira a espécie do caminho para o assunto permite alcançá-lo. Nesse sentido, o método fenomenológico-hermenêutico, ao invés de se conduzir por teorias pré-determinadas, se coloca como um método que se desdobra na abertura do ser no mundo e acompanha-o em um processo de compreensão.

Em vista dessa indeterminação para a qual a existência aponta e tomando como base o método fenomenológico-hermenêutico, é que se coloca em questionamento a discussão: como o processo de seleção pela Psicologia pode acarretar em diagnósticos, pareceres, inventários comportamentais, acerca desse homem que está sempre em jogo no seu devir temporal? Ao orientar seu fazer à forma descrita, consideramos que a Psicologia parece estar assim delimitando a existência em elementos restritos, impedindo o desvelamento de outras possibilidades, quando muito apresentando 
uma imagem parcial (porque temporária) do candidato à vaga de emprego. Antes, nesta reflexão compreende-se que este deve ser des-coberto a partir do modo como ele se apresenta por si-mesmo.

O caráter de indeterminação da existência elimina a possibilidade de equiparação entre o ser e o ente. Neste, a existência se dá por um conjunto de coisas simplesmente dadas, ordenadas pela facticidade da existência. $\mathrm{O}$ ser, por sua vez, se apresenta como "o ente privilegiado tanto ôntica, quanto ontologicamente" (Feijoo, 2011), sendo lançado às circunstâncias do mundo, mas dotado do seu poder-ser e sem categorizações prévias. Ao concentrar suas ações em avaliações quantitativas e prognósticos, supostamente, precisos e derivados de determinações prévias, a Psicologia parece reforçar uma concepção de homem constituído como um ente entre os demais entes, determinado por causas externas e, portanto, passível de manipulação e controle.

A Psicologia, ao orientar seu fazer pelo método científico e aderindo às determinações do horizonte histórico no qual se encontra imersa, considera como a verdade no processo seletivo o simplesmente dado, o que é oferecido ao conhecimento do que interessa investigar na prescrição histórica da atualidade. Desse modo, ela reduz a verdade do seu fazer ao que se apresenta como essas determinações, ou seja, o desvelamento do candidato ao posto de trabalho se dá pelo deduzido da proposição estabelecida no horizonte histórico atual, considerando o candidato apenas pelo modo como ele se mostra na evidência desse horizonte. Esquece-se, contudo, que o homem guarda em si uma totalidade que vai além do que a era da técnica determina como verdade e que, na indeterminação da existência, esse homem pode se apresentar de variados modos, velando-se e desvelando-se, ocultando-se e descobrindo-se no aberto dessa relação, sendo estes, na perspectiva heideggeriana, modos possíveis de o homem estar no mundo. Amordaçada pelas determinações prévias da era da técnica, a Psicologia parece se esquecer da essência da verdade enquanto liberdade de deixar-ser do ente, de mostrar-se naquilo que é.
Esse modelo de relacionamento homemtrabalho da atualidade também é matéria de discussão, sob outros vieses, de estudiosos como Sennett (2006, 2012), Dejours (1992, 2005) e Schwartz (2003, 2010a, 2010b, 2010c). O primeiro retrata a fragmentação das instituições sociais, dentre elas o trabalho, e o imediatismo dos tempos modernos que vêm estabelecendo a cultura de um novo capitalismo em que o trabalhador, ao invés de ter o domínio do seu trabalho, se encontra, na verdade, a sua deriva, diante do mar de flutuação do emprego e as exigências por mudanças constantes.

Dejours (1992), por sua vez, toma a questão da luta constante em que o sujeito se encontra entre a realização do trabalho consoante seus próprios desejos versus a prescrição da tarefa, que muitas vezes está distante daquele real em que o trabalho acontece. Esse conflito psicodinâmico leva o trabalhador a inúmeras tensões, fazendo com que ele busque sistemas defensivos na convivência com os paradoxos do trabalho, de forma que possa manter sua saúde física e mental.

O filósofo francês Schwartz (2010a) também parte das concepções sobre trabalho prescrito versus trabalho real, discutidas por Dejours (1992), mas radicaliza ao postular que o trabalho não existe se não implicar atividade, em ação, uma vez que ele se encontra envolvido pela vida e pelo homem, com todas as ambiguidades de que eles se investem. Schwartz (2010c) desenvolve também ricas considerações acerca da noção de competência e no modo como ela é tomada nos processos de gestão de pessoas na modernidade. Para ele, a concepção de competência, embora se colocando como um conceito inovador, parece se articular da mesma forma que no período taylorista, ao procurar nos determinantes dos cargos os requisitos indispensáveis ao êxito do trabalho e na análise do trabalhador os indicadores de sua aderência a tal cargo. Ao delimitar de forma precisa os requisitos de um lado e o assentimento comportamental do candidato por outro, acabamos por nos perder em delimitações de algo que não é delimitável, dada a complexidade que envolve o trabalho 
e o trabalhador. Schwartz (2003) propõe um modelo de análise por competência que inclua o descritível do trabalho, mas também a dimensão da experiência e da singularidade, articulando-os em sinergia.

Em todos esses autores, parece se mostrar uma intenção em retomar a concepção de trabalho imbuída da autonomia do homem, de devolver a este o controle daquilo que é seu, dado o caráter amplamente humano em que o trabalho se dá.

Martin Heidegger (2012), por sua vez, ao tematizar a inseparabilidade homem-mundo, temporaliza essa relação, tomando-a na historicidade em que ela acontece e na indissociabilidade de sua copertença. Nesse sentido, analisar o fenômeno do processo de seleção pela Psicologia, requer compreendê-lo no modo como ele acontece na existência, em que homem e mundo se constituem e são constituídos em um mesmo horizonte histórico.

Ao empreender-se um estudo crítico do processo de seleção pela Psicologia, pretende-se caminhar pela mesma concepção de crítica em Heidegger, que procura tratar o tema a ser abordado como diferenciação, uma vez que ele se desdobra em referência a algo previamente conceptualizado, porém a partir de sua definição usualmente dada, no modo como ele se dá no cotidiano da existência.

A palavra crítica provém do grego

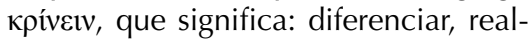
çar. A verdadeira crítica não é criticar no sentido de apontar falhas, repreender, depreciar. Crítica como diferenciação significa: deixar ver o diferente como tal em sua diferença. O que é diferente só o é uma vez que é diferente com referência a algo. Neste sentido, vemos primeiro o mesmo com referência ao qual o diferente faz parte. [...] Em outras palavras, a verdadeira crítica, como este deixar ver, é algo eminentemente positivo (Heidegger, 2009, pp. 111-112).

O estudo crítico aqui apresentado adquire, desse modo, uma conotação baseada nas mesmas concepções heideggerianas: não se trata de destruir o modelo cientificista do fazer da seleção psicológica ou de depreciá-lo, mas de se partir desse modelo de correção para estabelecer com ele uma relação de alteridade, de diferenciação. Trata-se de questionar o fazer da seleção de pessoal na modernidade, sobretudo em relação a como a concepção tradicional de verdade se coloca em jogo nesse processo e analisar sua prática dentro de um contexto que encontra na era da técnica o pano de fundo de suas significações. Ou seja, respirar outro ar, porém dentro do ar historial.

Ao problematizar o modelo de seleção de pessoal pela Psicologia que toma como verdade a adequação entre o perfil exigido para o bom desempenho no trabalho e as características daquele que tem pretensão em assumir uma atividade laboral, aliado à utilização de técnicas como instrumentos capazes de extrair as características mais próprias do candidato, acredita-se poder abrir um espaço de reflexão acerca das possibilidades e limites da atuação do psicólogo na seleção de pessoal, no qual novas possibilidades possam surgir.

\section{Considerações finais}

Por meio da análise da trajetória da organização do trabalho e sua interface com a Psicologia, procuramos esclarecer o domínio da concepção de verdade como adequação e correção e o caráter técnico instrumental que vem sustentando a Psicologia no modo de realização da seleção de pessoal. Assim, esclareceu-se o modo como o processo de seleção de pessoal se estabeleceu, em meio às determinações de sentido nesta que Martin Heidegger denominou a era da técnica.

Esse filósofo descreve a época em que vivemos como uma era que se caracteriza essencialmente pela ênfase no pensamento técnico-calculante, em que todas as coisas são tomadas pelo caráter da mensuração e calculabilidade. Nesse sentido, afirma-se que a era moderna detém algumas características, como: fundo de reserva, funcionalidade (serventia) e a produtividade sem limites. Esse modelo de pensamento tem um 
impacto direto na realização do processo de seleção de pessoal pela Psicologia, haja vista ser esse o critério básico exigido para que o trabalhador seja aprovado. Ocorre que, ao tomar esse critério como a única e absoluta verdade da capacidade do trabalhador, outras capacidades e motivações, quando muito, ficam relegadas a um segundo plano. O homem tomado pela determinação da produtividade passa a se comportar de modo autômato, tal como as máquinas, cuja utilidade dura enquanto durar a necessidade de sua produção, sendo descartado quando outras necessidades se sobrepõem àquela.

Por fim, por meio de uma visada fenomenológico-hermenêutica, pudemos, enfim, refletir sobre o processo de seleção em Psicologia e compreender como esta, ao ser constantemente interpelada pela era da técnica, vem tomando os atributos dessa era como verdades absolutas e, assim, estabelecendo seu fazer em seleção de pessoal sob essas verdades. Ao orientar seu fazer por esse modo, a Psicologia, no entanto, acaba por consolidar uma relação homem-trabalho em bases preponderantemente deterministas e, como tal, aprisionadoras. Assim, a Psicologia, comprometida com o processo de seleção, compactua, sedimenta e fortalece essa forma de pensar em que o homem é tomado como objeto de produção tal qual a máquina. A proposta aqui desenvolvida consiste em evidenciar a possibilidade de outra posição da Psicologia frente ao modo de estabelecimento do processo de seleção, de forma a poder resistir à perspectiva de homem apenas como um fator produtivo.

Pensar o processo de seleção de pessoal é pensar o homem e sua relação com o trabalho, na forma de sua empregabilidade, dentro de um horizonte histórico no qual esta se situa. Nessa perspectiva, essa discussão destaca a relevância social do tema ao apontar para a importância do modo de se fazer seleção de pessoal dentro de um contexto fortemente marcado pela imprevisibilidade do emprego e por novas estruturas de inserção do trabaIhador no cenário econômico da atualidade. Ressalta-se ainda a dinamicidade que vive hoje o mercado de trabalho em termos de transitoriedade, com o vínculo empregatício cada vez mais flexível e superficial, mas que, paradoxalmente, exige dos trabalhadores níveis sempre elevados de comprometimento com a empresa, de forma a se alcançar a esperada produtividade.

Outro olhar para o qual dirigimos nosso estudo refere-se ao atributo que é concedido atualmente ao estatuto profissional. Vive-se hoje o mundo da técnica, evocado por Heidegger (2007), em que a produtividade é que dá o tom ao modo de ser do homem, conforme mencionamos. Porém, em uma sociedade que desconhece limites e que se movimenta na busca de uma produção incessante, não basta ainda ao homem ter um emprego. Deve ser um emprego que o faça se destacar em meio ao competitivo ambiente corporativo. Caso contrário, esse homem é tomado como um fracassado ou incompetente e corre o risco de ser colocado à margem do sistema social.

Acrescente-se ainda a importância que, a despeito de todas as contradições, é atribuída ao emprego. Com a destituição de alguns valores coletivos, como a família, a religião e o convívio social espontâneo (sem o intermédio da técnica), o ambiente de trabalho é onde, hoje, o indivíduo encontra o seu senso de comunidade, que lhe concede a sensação de copertencimento, em que pode desfrutar dos valores coletivos, encontrar-se em uma comunidade e compartilhar com ela a sua essência de pessoa. Como apontam Freitas, Heloani, \& Barreto (2008),

Com ênfase cada vez maior a recair
sobre o aspecto econômico e o pau-
latino enfraquecimento de outras insti-
tuições sociais, a relação do indivíduo
com o seu emprego tornou-se pratica-
mente a sua fonte principal de iden-
tidade social e pessoal, uma vez que
esse indivíduo foi reduzido a seu papel
profissional, e é no ambiente de traba-
lho que ele vivencia a concretude de
alguns valores coletivos (p. 8 )

Se excluído desse contexto, o homem se vê também mutilado da capacidade de compartilhar e fazer parte de uma coletividade, 
o que, na ausência de reconhecimento pelo olhar do outro, torna inevitável o sentimento de nulidade e todas as consequências advindas dele. Em síntese, no moderno mundo da técnica, o estatuto da produção é o que, supostamente, garante o trabalhador do risco da exclusão.

Não se pretendeu, neste trabalho, apontar caminhos outros para o fazer da Psicologia no âmbito do trabalho, mas meditar sobre esse fazer, adotando outros elementos à discussão que dialogue com os princípios de uma filosofia fenomenológico-hermenêutica, ampliando, assim, o olhar crítico da Psicologia no que diz respeito a sua tarefa de selecionar pessoas para postos de trabalho. Acredita-se, assim, que é possível continuar a pensar em uma Psicologia cujo fazer em seleção de pessoal caminhe na direção de uma concepção de homem não visado apenas pelo seu caráter produtivista. Mas o homem, tomado em seu caráter de liberdade e revestido da indeterminação própria da existência que é, possa se mostrar naquilo que é fonte de sua motivação. $\mathrm{E}$, dessa forma, poder, cada um conquistar a coragem de aceder a sua verdade mais própria, ou seja, aquilo que em seu fazer faz sentido em sua existência, que como tal guarda em seu âmbito o seu caráter finito e transitório. 


\section{Ana Maria Lopez Calvo de Feijoo}

Doutora em Psicoterapias Atuais pela Universidade Federal do Rio de Janeiro, Rio de Janeiro - RJ. Brasil. Docente da Universidade do Estado do Rio de Janeiro, Rio de Janeiro - RJ. Brasil.

E-mail: ana.maria.feijoo@gmail.com

\section{Elina Eunice Montechiari Pietrani}

Mestre em Psicologia Social pela Universidade do Estado do Rio de Janeiro, Rio de Janeiro - RJ. Brasil.

\section{Endereço para envio de correspondência:}

Universidade do Estado do Rio de Janeiro, Departamento de Psicologia Clínica, Instituto de Psicologia. Rua São Francisco Xavier, 524. Maracanã. CEP: 20550-013. Rio de Janeiro - RJ. Brasil.

Recebido 15/03/2014, Reformulação 20/10/2014, Aprovado 08/12/2014. 


\section{Referências}

Cabral, A. M. (2004). A mãe das verdades: A originalidade e a originariedade do conceito de verdade em Heidegger. Rio de Janeiro, RJ: Forense Universitária.

Casanova, M. A. (2006). Nada a caminho: Impessoalidade, niilismo e técnica na obra de Martin Heidegger. Rio de Janeiro, RJ: Forense Universitária.

Castañon, G.A. (2004). Pós-modernismo e política científica na psicologia contemporânea: Uma revisão crítica. Temas em Psicologia da SBP, 12(2), 155-167.

Chiavenato, I. (2010). Gestão de pessoas (3a ed.). Rio de Janeiro, RJ: Elsevier.

Dejours, C. (1992). A loucura do trabalho: estudo de psicopatologia do trabalho (5a ed., A.I. Paraguay \& L.L.Ferreira, trads.). São Paulo. SP: Cortez.

Dejours, C. (2005). O fator humano. (5a ed., M. I. S. Betiol \& M. J. Tonelli, Trads.). Rio de Janeiro, RJ: Editora FGV.

Dejours, C., Abdoucheli, E., \& Jayet, C. (2012). Psicodinâmica do trabalho: Contribuições da escola dejouriana à análise da relação prazer, sofrimento e trabalho (M. I. S. Betiol, trad.). São Paulo, SP: Atlas.

Feijoo, A. M. L. C. (2011). A existência para além do sujeito: A crise da subjetividade moderna e suas repercussões para a possibilidade de uma clínica psicológica com fundamentos fenomenológico-existenciais. Rio de Janeiro, RJ: Edições IFEN.

Freitas, M. E., Heloani, R. S., \& Barreto, M. (2008). Assédio moral no trabalho. (Coleção Debates em Administração). São Paulo, SP: Cengace Learning.

Heidegger, M. (1991). Meu caminho para a fenomenologia. In: Os pensadores (E. Stein, trad., pp. 450-500). São Paulo: Nova Cultural. (Trabalho original publicado em 1963).

Heidegger, M. (2007). A questão da técnica. Scientiae Studia, 5(3), 375-398. Recuperado em 18 de novembro de 2011, de http:// www.scientiaestudia.org.br/revista/ PDF/05_03_05.pdf.

Heidegger, M. (2009.) Seminários de Zollikon. (G. \& M..A. Prado, trad.). Petrópolis, RJ: Vozes.
Heidegger, M. (2012). Ser e tempo. (6a ed,, M.S. C. Schuback, trad.). Petrópolis, RJ: Vozes. (Trabalho original publicado em 1927).

Leme, R. (2007). Seleção e entrevista por competências com o inventário comportamental: Guia prático do processo seletivo para a redução da subjetividade e eficácia na seleção. Rio de Janeiro, RJ: Qualitymark.

Lima, F. C., Costa, A. L. F., \& Yamamoto, O. H. (2011). O exercício profissional do psicólogo do trabalho e das organizações: Uma revisão da produção científica. Psicologia: Organizações e Trabalho, jul./dez. /2011. Recuperado em 8 de novembro de 2012, de http://submission-pepsic.scielo.br/index. php/rpot/index

Pontes, B. R. (2010) Planejamento, recrutamento e seleção de pessoal (6a ed.) São Paulo, SP: LTr.

Ribeiro, E. C. (2008) Temor e enfrentamento como paradoxos de uma existência. In A. M. L. C. Feijoo (Org.), Interpretações fenomenológico-existenciais para o sofrimento psíquico na atualidade (pp. 151181). Rio de Janeiro, RJ: GdN Ed.

Rodrigues, A., Assmar, E. M. L., Jablonski, B. (2012). Psicologia social (29a ed.) Petrópolis, RJ: Vozes.

Schwartz, Y. (2003) O trabalho numa perspectiva filosófica. Seminário Trabalho, Saber, Educação. Cuiabá. (M.-A. Bernier, trad.). Recuperado em 27 de março de 2013, de http://pt.scribd.com/doc/190888321/OTrabalho-Numa-Perspectiva-FilosoficaSchwartz\#download

Schwartz, Y. (2010a). Trabalho e uso de si. In Y. Schwartz, \& L. Durrive (Orgs.), Trabalho e ergologia: Conversas sobre a atividade humana (pp. 189-204). Niterói, RJ: EdUFF.

Schwartz, Y. (2010b). Uso de si e competência. In Y. Schwartz, \& L. Durrive (Orgs.), Trabalho e ergologia: Conversas sobre a atividade humana (pp. 205-221). Niterói, RJ: EdUFF.

Schwartz, Y. (2010c). A linguagem em trabalho. In Y. Schwartz, \& L. Durrive (Orgs.), Trabalho e ergologia: Conversas sobre a atividade humana (pp. 131-164). Niterói, RJ: EdUFF. 
Sennett, R. (2006). A corrosão do caráter: Consequências pessoais do trabalho no novo capitalismo (11a.ed., M. Santarrita, trad.). Rio de Janeiro, RJ: Record.
Sennett, R. (2012). A cultura do novo capitalismo (4a ed., C. Marques, trad.). Rio de Janiero, RJ: Record. 